\title{
Early surgery for Hong Kong Chinese elderly patients with hip fracture reduces short-term and long-term mortality
}

\author{
Stephanie KK Liu, Angela WH Ho *, SH Wong
}

\section{A B S T R A C T}

Introduction: Studies have shown that early surgery reduces hospital and 1-year mortality in elderly patients with hip fracture, but no major study has examined such relationship in Hong Kong. This study aimed to explore the relationship of early surgery and mortality in a Chinese elderly population with hip fracture.

Methods: This observational study included patients attending public hospitals in Hong Kong. All patients who underwent surgery for geriatric hip fracture in public hospitals from January 2000 to December 2011 were studied. Data were retrieved and collected from the Clinical Data Analysis and Reporting System of the Hospital Authority. Patients were divided into three groups according to timing of surgery: early (0-2 days after admission), delayed (3-4 days after admission), and late ( $\geq 5$ days after admission) groups. Based on the date of death, we analysed 30-day and 1-year mortality, regardless of cause of death. Comparison of mortality rates was also made between the period before and after implementation of Key Performance Indicator formulated by the Hospital Authority.

This article was published on 28 Jun 2017 at www.hkmj.org.
Results: The overall 1-year mortality rate was $16.8 \%$. The relative risks of 1 -year mortality were 1.21 and 1.52 when the delayed and late groups were compared with the early group, respectively. The hazard ratios of long-term mortality were $1.16(95 \%$ confidence interval, 1.13-1.20) and 1.37 (1.33-1.41), respectively for the same comparison.

Conclusion: Prevalence of geriatric hip fracture will continue to rise and further increase the burden on our health care system. After implementation of Key Performance Indicator, most elderly patients with hip fracture underwent surgery within 2 days provided they were medically fit. Early surgery can reduce both short-term and long-term mortality. Setting up a fragility fracture registry would be beneficial for further studies.
Hong Kong Med J 2017;23:374-80
DOI: $10.12809 / \mathrm{hkmj} 165005$

\begin{abstract}
SKK Liu, MB, BS
${ }^{2}$ AWH Ho *, MB, ChB, FHKAM (Orthopaedic Surgery)

${ }^{2}$ SH Wong, MB, BS, FHKAM (Orthopaedic Surgery)
\end{abstract}

\section{Department of Orthopaedics and Traumatology, Princess Margaret Hospital, Laichikok, Hong Kong \\ ${ }^{2}$ Department of Orthopaedics and Traumatology, Caritas Medical Centre, Shamshuipo, Hong Kong}

An earlier version of this paper was presented at the Young Investigator Awards, 15th Regional Osteoporosis Conference held in Hong Kong on 24-25 May 2014; and at the International Osteoporosis Foundation (IOF) Young Investigator Awards, IOF Regionals 5th Asia-Pacific Osteoporosis Meeting held in Taipei, Taiwan on 15 November 2014.

* Corresponding author: angelaho@alumni.cuhk.net

\section{New knowledge added by this study}

- This study provides evidence that Key Performance Indicator (KPI) can increase the percentage of patients who undergo early surgery and improve their clinical outcome.

- Most medically fit patients were identified for early surgery within 2 days.

- High-risk patients with medical co-morbidities were identified for prompt preoperative optimisation under KPI.

- Early surgery should be considered the standard of care for management of elderly patients with hip fracture.

\section{Introduction}

Hip fracture has a high prevalence in an ageing population and places a major burden on and challenge to our health care system. In Hong Kong, the number of geriatric hip fractures managed in the Hospital Authority increased from 3678 in 2000 to 4579 in $2011 .^{1}$ International clinical guidelines recommend surgical treatment within 2 days of admission. ${ }^{2-4}$ Geriatric hip fracture was selected as the first Key Performance Indicator (KPI) for orthopaedics in Hong Kong by the Hospital Authority in 2009 with an aim to limit preoperative length of stay to no more than 2 days for $70 \%$ of patients with hip fracture. ${ }^{5}$ Studies have shown that early surgery reduces hospital and 1-year mortality in elderly patients with hip fracture, ${ }^{6-8}$ but no major study has examined such relationship. This study was conducted to explore the relationship of early surgery and mortality in a Chinese elderly population with hip fracture. 


\section{Methods}

We undertook a retrospective review of data collected from the Clinical Data Analysis and Reporting System of the Hospital Authority of Hong Kong for all patients aged 65 years or above who presented to any public hospital between January 2000 and December 2011 with hip fracture that was treated surgically. Those patients with a disease coding of acute hip fracture (ICD-9-CM diagnosis codes 820.8, 820.09, 820.02, 820.03, 820.20, and 820.22) were retrieved; operations for geriatric hip fracture were defined as a patient episode with ICD9-CM procedure codes of $81.52,51.51,81.40,79.15$, 79.35 , or 78.55 . Only elderly patients with a disease code for acute hip fracture and procedure code for hip fracture surgery were included in the current study. Those who had second hip fracture surgery or surgery for complications arising from a previous hip fracture were excluded.

Patients were divided into three groups according to timing of surgery: early (0-2 calendar days after admission), delayed (3-4 calendar days after admission), and late ( $\geq 5$ calendar days after admission) groups. Dates of death were retrieved from the Deaths Registries of the Hong Kong SAR. Based on the date of death, we analysed the 30-day and 1-year mortality regardless of cause. Mortality was calculated using Kaplan-Meier survival analysis. Among the three groups, the 30-day and 1-year mortality were compared using Chi squared test. Long-term mortality was compared by Cox regression models using age, gender, and year as covariates. Subgroup analysis of mortality before (year 2000-2008) and after (year 2009-2011) the execution of KPI for hip fracture was also performed. The result was considered statistically significant if

TABLE I. 30-Day and I-year mortality of patients by gender (all $\mathrm{P}<0.00 \mathrm{I}$ )

\begin{tabular}{lccc}
\hline & $\begin{array}{c}\text { No. (\%) of } \\
\text { patients }\end{array}$ & $\begin{array}{c}\text { 30-Day } \\
\text { mortality (\%) }\end{array}$ & $\begin{array}{c}\text { 1-Year } \\
\text { mortality (\%) }\end{array}$ \\
\hline Male & $12821(29)$ & 5.2 & 25.0 \\
Female & $31009(71)$ & 2.3 & 13.4 \\
Overall & $\mathbf{4 3 8 3 0}$ & $\mathbf{3 . 1}$ & $\mathbf{1 6 . 8}$ \\
\hline
\end{tabular}

\section{早期手術可減低華籍老年顝部骨折術後的短期及 長期死亡率 \\ 廖珈琪、何穎恆、黃仕雄}

引言：研究顯示早期手術可降低髖部骨折的老年患者其住院及一年死 亡率, 可惜香港並未有類似研究。本研究探討髖部骨折的老年患者接 受早期手術和死亡率的關係。

方法：本觀察研究的對象是從2000年1月至2011年12月期間到香港公 立醫院接受哯部骨折手術的老年患者。從醫院管理局的臨床數據分析 和報告系統中收集所需數據, 根據入院後進行手術的時間把病人分為 三組：早期手術（即入院後 0 至 2 天）、延遲手術（入院後 3 至 4 天）和 晚期手術（入院後 5 天或以上）。在不考慮死亡原因的情況下, 按病 人死亡日期得出 30 天和 1 年死亡率, 並比較醫院管理局制定的主要績 效指標落實前後的死亡率。

結果：總體 1 年死亡率為 $16.8 \%$ 。與早期手術組別比較, 延遲手術組別 和晚期手術組別的 1 年死亡率的相對危險度分別為 1.21 和 1.52 ; 而長期 死亡的風險比分別為1.16（95\%置信區間，1.13-1.20）和 1.37 ( $1.33-$ 1.41 )

結論：老年髖部骨折的患病率持續上升, 進一步增加醫療保健系統的 負擔。本研究發現實施主要績效指標後, 如果身體狀況合適, 大多數 髖部骨折的老年患者可以在兩天內進行手術。早期手術可以減少病人 的短期和長期死亡率。建立脆性骨折登記處將有助進一步推進有關的 研究。

the $P$ value was $<0.05$. All analyses were performed using SAS version 9.3 (SAS Institute Inc, Cary [NC], US) software. The principles outlined in the Declaration of Helsinki have been followed.

\section{Results}

The study identified 43830 patients (12821 men and 31009 women) with age ranging from 65 to 112 years (mean, 82 years). Early surgery was performed in $48 \%$, delayed surgery in $25 \%$, and late surgery in $27 \%$ of all patients. The 30 -day and 1 -year mortality of the patients by gender and surgery group are listed in Tables 1 and 2, respectively. For each agegroup (65-69, 70-74, 75-79, 80-84, $\geq 85$ years), the percentage of early, delayed, or late surgery was similar with a deviation of only $1 \%$ to $2 \%$. Linear regression revealed no correlation between the timing of surgery and patient age. The 1-year mortality rate

TABLE 2. Mortality, excess mortality, and relative risk of patients by surgery group (all $P<0.00 \mathrm{I}$ )

\begin{tabular}{|c|c|c|c|c|c|c|c|}
\hline \multirow{2}{*}{$\begin{array}{l}\text { Surgery group (No. of } \\
\text { days after admission) }\end{array}$} & \multirow{2}{*}{$\begin{array}{l}\text { No. }(\%) \text { of } \\
\text { patients }\end{array}$} & \multicolumn{3}{|c|}{ 30-Day mortality (\%) } & \multicolumn{3}{|c|}{ 1-Year mortality (\%) } \\
\hline & & $\begin{array}{l}\text { 30-Day } \\
\text { mortality }\end{array}$ & $\begin{array}{c}\text { Excess } 30 \text {-day } \\
\text { mortality }\end{array}$ & Relative risk & $\begin{array}{l}\text { 1-Year } \\
\text { mortality }\end{array}$ & $\begin{array}{l}\text { Excess 1-year } \\
\text { mortality }\end{array}$ & $\begin{array}{l}\text { Relative } \\
\text { risk }\end{array}$ \\
\hline Early (0-2) & $20956(48)$ & 2.6 & -0.6 & - & 14.1 & -2.7 & - \\
\hline Delayed (3-4) & $11006(25)$ & 3.1 & -0.1 & 1.20 & 17.2 & 0.4 & 1.21 \\
\hline Late $(\geq 5)$ & $11868(27)$ & 4.2 & 1.1 & 1.66 & 21.4 & 4.6 & 1.52 \\
\hline
\end{tabular}




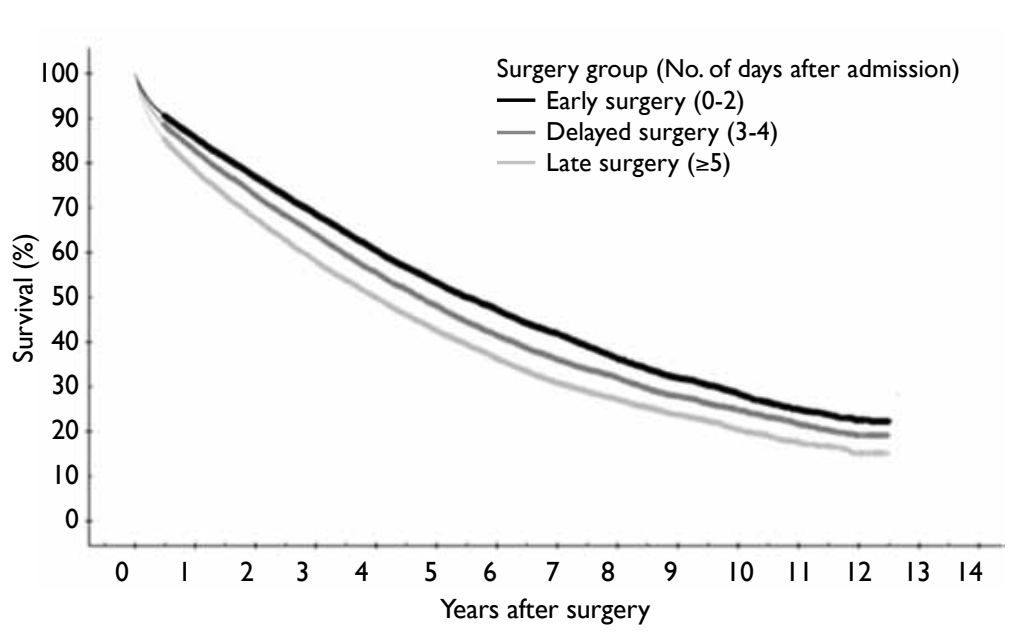

FIG I. Survival curves of patients with hip fracture in three surgery groups

TABLE 3. Hazard ratio of timing to surgery in different age-groups and by gender*

\begin{tabular}{|c|c|c|c|c|}
\hline \multirow{2}{*}{$\begin{array}{l}\text { Age-group } \\
\text { (years) }\end{array}$} & \multicolumn{2}{|c|}{ Male } & \multicolumn{2}{|c|}{ Female } \\
\hline & HR & $95 \% \mathrm{Cl}$ & HR & $95 \% \mathrm{Cl}$ \\
\hline \multicolumn{5}{|l|}{$65-69$} \\
\hline Early & - & - & - & - \\
\hline Delayed & 1.115 & $0.887-1.402$ & 1.314 & $1.014-1.704$ \\
\hline Late & 1.469 & $1.189-1.814$ & 1.515 & $1.178-1.946$ \\
\hline \multicolumn{5}{|l|}{$70-74$} \\
\hline Early & - & - & - & - \\
\hline Delayed & 1.349 & $1.148-1.586$ & 1.403 & $1.203-1.634$ \\
\hline Late & 1.581 & $1.355-1.846$ & 1.698 & $1.464-1.969$ \\
\hline \multicolumn{5}{|l|}{$75-79$} \\
\hline Early & - & - & - & - \\
\hline Delayed & 1.178 & $1.041-1.333$ & 1.164 & $1.053-1.289$ \\
\hline Late & 1.414 & $1.260-1.587$ & 1.435 & $1.302-1.582$ \\
\hline \multicolumn{5}{|l|}{$80-84$} \\
\hline Early & - & - & - & - \\
\hline Delayed & 1.220 & $1.096-1.359$ & 1.175 & $1.086-1.272$ \\
\hline Late & 1.365 & $1.235-1.508$ & 1.300 & $1.205-1.404$ \\
\hline \multicolumn{5}{|l|}{$\geq 85$} \\
\hline Early & - & - & - & - \\
\hline Delayed & 1.106 & $1.009-1.212$ & 1.121 & $1.062-1.185$ \\
\hline Late & 1.297 & $1.190-1.414$ & 1.289 & $1.222-1.361$ \\
\hline \multicolumn{5}{|l|}{ Overall } \\
\hline Early & \multicolumn{4}{|c|}{-} \\
\hline Delayed & \multicolumn{4}{|c|}{$1.16(1.13-1.20)$} \\
\hline Late & \multicolumn{4}{|c|}{$1.37(1.33-1.41)$} \\
\hline
\end{tabular}

Abbreviations: $\mathrm{Cl}=$ confidence interval; $\mathrm{HR}=$ hazard ratio

* All $\mathrm{P}<0.00$ I except male patients of 65-69 years in the delayed surgery group of all hip fractures was $16.8 \%$ (25.0\% for males and $13.4 \%$ for females). The 1-year mortality rates of early, delayed, and late surgery groups were $14.1 \%$, $17.2 \%$, and $21.4 \%$, respectively. The relative risks of 1-year mortality were 1.21 (95\% confidence interval [CI], 1.16-1.29) and 1.52 (95\% CI, 1.45-1.59) when the delayed and late groups were compared with the early group, respectively. All results were statistically significant.

The long-term mortality rate was also significantly related to the timing of surgery using $\log$ rank test (Fig 1). The hazard ratios (HRs) of longterm mortality were 1.16 (95\% CI, 1.13-1.20) and 1.37 (95\% CI, 1.33-1.41) when the delayed group and late group were compared with the early group, respectively. Such significant difference was observed across all age-groups for both genders, except those male patients of 65-69 years in the delayed surgery group (Table 3). In men, the respective HR was 1.121.35 and 1.30-1.58 when the delayed group and late group were compared with the early group, with the highest HR noted in the age-group of 70-74 years. Similar results were observed in females: the HR varied with age and ranged from 1.12-1.40 and 1.291.70 respectively when the delayed group and late group were compared with the early group, with the highest HR in the age-group of 70-74 years (Table 3).

Subgroup analysis of the mortality rate before (year 2000-2008) and after (year 2009-2011) execution of KPI for hip fracture was performed. Mortality rate increased as surgery delay was prolonged. The respective relative risk of 1-year mortality before KPI was 1.12 (95\% CI, 1.04-1.21) and 1.27 (95\% CI, 1.19-1.36) when the delayed group and late group were compared with the early group; the corresponding figures after KPI were 1.15 (95\% CI, $0.99-1.34)$ and 1.39 (95\% CI, 1.20-1.60). The overall 1 -year mortality was lower in the post-KPI group (relative risk $=0.81 ; \mathrm{P}<0.001 ; 95 \% \mathrm{CI}, 0.76-0.86$ ). All results were statistically significant (Table 4 ). There was also a gradual reduction in preoperative length of stay of elderly patients (age range, 65-112 years) with hip fracture in the post-KPI period (Fig 2).

\section{Discussion}

Hip fracture in elderly patients is well known to be associated with osteoporosis and sarcopenia. ${ }^{9,10}$ In an ageing population, it is becoming more important and places a great burden on our health care system. Timing of surgery for hip fracture is considered an important factor in reducing mortality. We therefore conducted this study to find out their relationship. To the best of our knowledge, this is the first large observational study of the association between timing of surgery and mortality of hip fracture in the local Chinese elderly population.

Current international guidelines and national model of care for geriatric hip fracture recommend 
TABLE 4. Overall mortality rate and subgroup analysis of the mortality rate before (year 2000-2008) and after (year 2009-20II) execution of Key Performance Indicator for hip fracture (all $P<0.00$ I)

\begin{tabular}{|c|c|c|c|c|c|c|c|c|}
\hline \multirow{2}{*}{$\begin{array}{l}\text { Surgery group } \\
\text { (No. of days after } \\
\text { admission) }\end{array}$} & \multicolumn{4}{|c|}{$2000-2008$} & \multicolumn{4}{|c|}{$2009-2011$} \\
\hline & $\begin{array}{c}\text { 30-Day } \\
\text { mortality (\%) }\end{array}$ & Relative risk & $\begin{array}{c}\text { 1-Year } \\
\text { mortality (\%) }\end{array}$ & Relative risk & $\begin{array}{c}\text { 30-Day } \\
\text { mortality (\%) }\end{array}$ & Relative risk & $\begin{array}{c}\text { 1-Year } \\
\text { mortality (\%) }\end{array}$ & Relative risk \\
\hline Early (0-2) & 2.08 & - & 10.81 & - & 1.91 & - & 9.21 & - \\
\hline Delayed (3-4) & 2.57 & 1.24 & 12.15 & 1.12 & 3.31 & 1.73 & 10.58 & 1.15 \\
\hline Late $(\geq 5)$ & 3.18 & 1.53 & 13.75 & 1.27 & 3.59 & 1.88 & 12.76 & 1.39 \\
\hline Overall & - & - & 12.1 & - & - & - & 9.83 & 0.81 \\
\hline
\end{tabular}

early surgery to improve the clinical outcome for elderly patients, including morbidity and mortality. The Blue Book of the British Orthopaedic Association in 2007 stated that hip fractures should be operated on within 48 hours. $^{2}$ The National Institute for Health and Care Excellence (NICE) Clinical Guideline (CG 124) from the United Kingdom recommends that surgery be performed on the day of, or the day after admission, based on the reason that early surgery within 24 or 48 hours is associated with a lower mortality risk. ${ }^{3}$ In Canada, access to surgery should be no later than 48 hours or 2 days after admission to the emergency room. ${ }^{4}$

Hip fracture is associated with high mortality among the elderly people, with excess mortality compared with the general population globally. ${ }^{11}$ Our study found that longer preoperative stay was associated with an overall increased 30-day, 1-year, and long-term mortality in the study population, as shown in Tables 2 and 3. Other studies have examined short-term mortality following surgery, with medical co-morbidities adjusted. Colais et $\mathrm{al}^{7}$ reported that patients who underwent surgery within 2 days had a lower 1-year mortality than those in whom surgery was delayed $(\mathrm{HR}=0.83 ; 95 \% \mathrm{CI}$, $0.82-0.85)$. Moja et $\mathrm{al}^{12}$ performed a meta-analysis of 35 studies and found that early surgery $(<2$ days of admission) had significantly less mortality, with the odds ratio (OR) being 0.74 (95\% CI, 0.67-0.81; $\mathrm{P}<0.001)$. In cases with more than 2 days of delay, the OR for death in hospital was 1.43 (95\% CI, 1.37-1.49) and 30-day mortality was 1.36 (95\% CI, 1.29-1.43)..$^{13}$ Sund and Liski ${ }^{14}$ found that delay of more than 2 nights led to a significant increase in mortality; the HR for late surgery was 1.18 (95\% CI, 1.09-1.28, $\mathrm{P}<0.0001)$. Similar findings were also reported from other studies. Delay of surgery affected both shortterm and long-term mortality. ${ }^{15-17}$ In our study, the HRs for delayed surgery and late surgery were 1.16 and 1.37, respectively, similar to other large-scale international studies. ${ }^{14,16}$ The longer the delay in surgery, the worse the clinical outcome.

Most studies in the current literature have focused on short-term mortality following surgery in patients with hip fracture, but it is known that

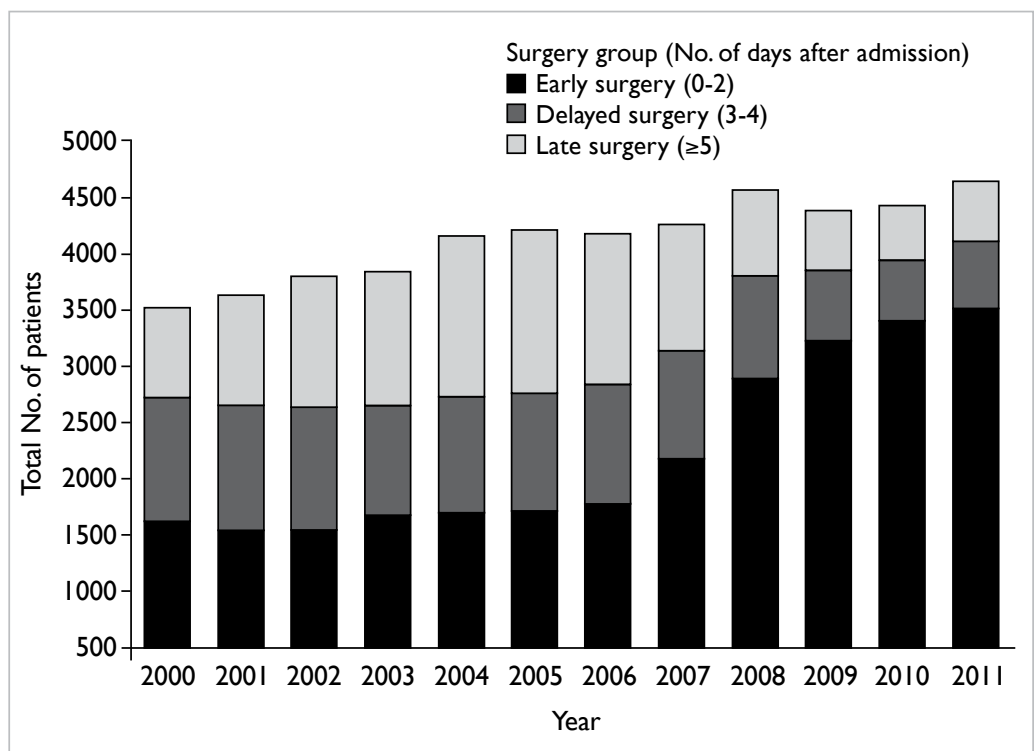

FIG 2. Trend of preoperative length of stay from 2000-20II

mortality in those elderly patients with hip fracture is high not only in the first year following fracture, but also remains higher than the general population during the subsequent 5 years of follow-up in some studies. Man et $\mathrm{al}^{1}$ reported a 1-year excess mortality following surgery for geriatric hip fracture of $6.22 \%$ to $23.45 \%$. In our study, the beneficial effects of early surgery on mortality were not only limited to the first year after initial fracture, but extended to later years after the injury based on the calculation using survival analysis (Fig 1). Our results showed that the HRs of long-term mortality were $1.16(95 \%$ CI, 1.13-1.20) and 1.37 (95\% CI, 1.33-1.41) when the delayed group and late group were compared with the early group, respectively. This significant result was observed across all age-groups for both genders (Table 3), despite advancing age and male gender being associated with increased mortality and higher excess mortality following hip surgery. ${ }^{1}$ Thus, early surgery for hip fracture among elderly patients is justified to relieve pain, reduce complications, 
and improve survival; this echoes our current local guidelines from the Hospital Authority., 46,18,19

Key Performance Indicator was a framework formulated by the Hospital Authority in 2008 and covered three areas, including Clinical Services, Human Resources, and Finance. For each area, it covers a collection of selected indicators. Annual reviews are conducted by a working group to ensure the KPIs are in line with the service directions and priorities of the Hospital Authority. Through comments and feedback collected from different sources, the working group reviews the results and offers suggestions and recommendations for subsequent service development and resource allocation, in order to provide the best service and practices for the general public. With the implementation of the KPI, hospitals gradually operated on hip fractures as an emergency or earlier under the supervision of more experienced orthopaedic surgeons. In the past, it was not uncommon for hip fracture surgery to be performed by junior orthopaedic surgeons in an emergency setting after office hours. According to the Blue Book of the British Orthopaedic Association, "all patients with hip fracture who are medically fit should have surgery within 48 hours of admission, and during normal working hours". To correctly interpret the best practice guideline, timing of surgery is an important consideration that can improve outcome. Therefore, emergency daytime surgery under supervision is preferable. Prior to 2007 the KPI was approximately $30 \%$, but it had improved to $71.6 \%$ by $2015 .^{20}$ As a result, length of hospital stay, and postoperative mortality and morbidity were reduced in our population. ${ }^{18}$

Figure 2 shows the gradual reduction in preoperative length of stay of elderly patients (age range, 65-112 years) with hip fracture after implementation of KPI. Lau et $\mathrm{al}^{21}$ identified preoperative length of stay as one of the most important factors to affect clinical outcomes of elderly patients with hip fracture. This was confirmed by our study. After the introduction of KPI for geriatric hip fracture, there was a reduced preoperative stay, and improved survival with reduced 1-year mortality (Table 4). This was likely because patients were able to mobilise sooner with consequent faster recovery and rehabilitation. Advances in surgical techniques, improved perioperative care, and a multidisciplinary approach allowed high-risk elderly patients to undergo early surgery.

Since the execution of KPI, the percentage of medically fit patients operated on early has increased by approximately $30 \%$ to over $70 \%{ }^{5,18}$ As a result, the overall 1-year mortality was significantly lower in the post-KPI group. Our current data reveal that the KPI was successful in allowing more patients to have earlier surgery with a consequent better clinical outcome. Unnecessary delay for surgery was avoided.

One of the reasons for a delay in surgery was medical fitness. It is not uncommon for geriatric patients to be admitted with an acute medical comorbidity, such as chest infection. This group of patients has complex care needs and a higher risk of morbidity and mortality. ${ }^{11}$ Surgery is often delayed due to the need for a medical condition to be stabilised. We therefore performed a subgroup analysis of 1-year mortality in patients before and after KPI. Our results showed that after the implementation of KPI, the increased relative risk of mortality for delayed surgery was even more pronounced (Table 4).

A recent retrospective analysis of prospectively collected data published by Nyholm et $\mathrm{al}^{22}$ revealed that patients who underwent delayed surgery had more co-morbidities, and those with a higher American Society of Anesthesiologists (ASA) score often waited longer for surgery. One of the postulated reasons was preoperative optimisation of their medical condition. Nonetheless they were able to show an association between surgical delay and risk of mortality even after adjustment for ASA score, indicating that there was an increased risk of mortality with increasing surgical delay, but not due to decreasing medical fitness of patients with longer delay times only. ${ }^{23} \mathrm{~A}$ systematic review and meta-analysis by Moja et $\mathrm{al}^{12}$ of 35 retrospective and prospective studies examined the association between mortality and delayed surgery in hip fracture among elderly patients. Meta-analysis of the primary outcome of overall mortality showed that early surgery ( $<2$ days of admission) had significantly less mortality with an OR of 0.74 (95\% CI, $0.67-$ $0.81 ; \mathrm{P}<0.001)$. Meta-analysis of only prospective studies gave similar results $(\mathrm{OR}=0.69 ; 95 \% \mathrm{CI}, 0.57$ 0.83 ), and further analysis did not show any effect of potential confounders such as age or gender. Despite some intra-study heterogeneity, these authors concluded that early surgery was associated with overall lower mortality risk, consistent with the current recommendation in national guidelines..$^{2-4}$

In order to achieve early preoperative optimisation, collaboration with orthogeriatricians is important. The National Hip Fracture Database annual report in 2015 revealed that $85.3 \%$ of people with hip fracture received orthogeriatric assessment in the perioperative period. Such service, however, was not available in all orthopaedic units..$^{23}$ The NICE Clinical Guideline (CG 124) recommends early input from orthogeriatricians in the management of patients with hip fracture. ${ }^{3}$ They play a key role in the integration of initial assessment and perioperative care as most elderly patients with hip fracture have co-morbidities. Leung et $\mathrm{al}^{24}$ found that input from geriatricians in the pre- and post-operative periods 
resulted in reduced 1-year mortality $(11.5 \%$ for orthogeriatric group vs $20.4 \%$ for conventional group; $\mathrm{P}=0.02$ ) and improved functional outcome in elderly patients with hip fracture. In the study of Vidán et $\mathrm{al}^{25}$ patients assigned to the geriatric intervention showed a lower hospital mortality $(0.6 \%$ vs $5.8 \%$; $\mathrm{P}=0.03)$ and major medical complication rate $(45.2 \%$ vs $61.7 \% ; \mathrm{P}=0.003)$ compared with the usual care group. Similar findings are evident in many other reports. ${ }^{26-28}$

Orosz et $\mathrm{al}^{29}$ classified reasons of delay in surgery into patient-related or system-related. Delay related to stabilisation of medical co-morbidities may sometimes be inevitable, but operative delay would undoubtedly have a significant impact on survival. Based on this observational study, we were able to conclude that KPI was successful in allowing more medically fit patients to undergo surgery without delay and therefore lead to improved clinical outcomes. Surgery may be delayed in highrisk patients to enable optimisation of medical conditions, and involves close collaboration with orthogeriatricians.

In future studies, further subgroup analysis of patients with different ASA grade and number of co-morbidities is warranted so that causes of excess mortality and high-risk patients can be recognised and early interventions performed to reduce their risk. Potential confounding factors should also be identified as far as possible so they can be controlled and matched in future studies. The setting up of a fragility fracture registry would be beneficial for further studies and analysis.

\section{Limitations}

This study has several limitations. First, factors affecting mortality-for example, pre-injury mobility status, medical co-morbidities, ASA grade, functional status, and fracture type-were not adjusted. It is known that patients with active medical co-morbidities have higher morbidity and mortality. ${ }^{15}$ Medical fitness is one of the major confounding factors in delayed surgery. Patients who are medically fit generally undergo surgery earlier, and those with medical co-morbidities may be delayed for preoperative assessment and stabilisation.

Second, a small percentage of geriatric hip fracture patients who were treated in the private sector was not included. This, however, would not have had a large impact on the overall results as approximately $98 \%$ of elderly patients with hip fracture are managed in public hospitals under the Hospital Authority. We believe our data are an accurate reflection of hip fracture cases in Hong Kong. ${ }^{30}$

Third, like many database systems for hospital data, deaths out of Hong Kong were not captured, leading to underreported hospital mortality.

Fourth, the current observed association between early operation and reduced mortality rate might have been substantially confounded by improved operative techniques and choice of implant (eg use of cemented hemiarthroplasties for relatively younger and medically fit elderly patients with femoral neck fractures), early involvement from orthogeriatricians, and improved general medical care. Undoubtedly all these factors within the current improved clinical pathway have played an important role in the improved clinical outcomes in the later (post-KPI) period of this study.

Lastly, reasons for delay in operation were not determined in this study.

\section{Conclusion}

The present observational study found that KPI has successfully increased the percentage of patients undergoing early surgery within 2 days so as to improve clinical outcome, with one of the parameters being mortality. Collaboration with orthogeriatricians will allow early preoperative optimisation of high-risk patients with medical co-morbidities. With an expected increase in the incidence of geriatric hip fracture, good practice of KPI with early surgery should be offered to these patients. Guidelines, clinical pathways, and the setting up of a fragility fracture registry can all play a significant role in improving our health care system.

\section{Acknowledgements}

The authors would like to thank Dr CP Chan for the statistical analysis, and Mr Tony Kwok and the Clinical Data Analysis and Reporting System team of Hospital Authority for their help in data retrieval.

\section{Declaration}

All authors have disclosed no conflicts of interest.

\section{References}

1. Man LP, Ho AW, Wong SH. Excess mortality for operated geriatric hip fracture in Hong Kong. Hong Kong Med J 2016;22:6-10

2. The care of patients with fragility fracture. British Orthopaedic Association. September 2007. Available from: http://www.fractures.com/pdf/BOA-BGS-Blue-Book.pdf. Accessed Jun 2016

3. Hip fracture: management. Clinical guideline. National Institute for Health and Care Excellence (NICE). 22 June 2011. Available from: https://www.nice.org.uk/guidance/ cg124. Accessed Jun 2016.

4. Bone and Joint Decade Canada. National hip fracture toolkit. June 30 2011. Available from: http:// boneandjointcanada.com/wp-content/uploads/2014/05/ National-hip-fracture-toolkit-June-2011.pdf. Accessed Jun 2016.

5. Report of the chairman. COC in orthopaedics and 
traumatology. Hong Kong: Hospital Authority; 2009.

6. Shiga T, Wajima Z, Ohe Y. Is operative delay associated with increased mortality of hip fracture patients? Systematic review, meta-analysis, and meta-regression. Can J Anaesth 2008;55:146-54.

7. Colais P, Di Martino M, Fusco D, Perucci CA, Davoli M. The effect of early surgery after hip fracture on 1-year mortality. BMC Geriatr 2015;15:141.

8. Zuckerman JD, Skovron ML, Koval KJ, Aharonoff G, Frankel VH. Postoperative complications and mortality associated with operative delay in older patients who have a fracture of the hip. J Bone Joint Surg Am 1995;77:15516.

9. Tsang SW, Kung AW, Kanis JA, Johansson H, Oden A. Ten-year fracture probability in Hong Kong Southern Chinese according to age and BMD femoral neck T-scores. Osteoporos Int 2009;20:1939-45.

10. Ho AW, Lee MM, Chan EW, et al. Prevalence of presarcopenia and sarcopenia in Hong Kong Chinese geriatric patients with hip fracture and its correlation with different factors. Hong Kong Med J 2016;22:23-9.

11. Moran CG, Wenn RT, Sikand M, Taylor AM. Early mortality after hip fracture: is delay before surgery important? J Bone Joint Surg Am 2005;87:483-9.

12. Moja L, Piatti A, Pecoraro V, et al. Timing matters in hip fracture surgery: patients operated within 48 hours have better outcomes. A meta-analysis and meta-regression of over 190,000 patients. PLoS One 2012;7:e46175.

13. Bottle A, Aylin P. Mortality associated with delay in operation after hip fracture: observational study. BMJ 2006;332:947-51.

14. Sund R, Liski A. Quality effects of operative delay on mortality in hip fracture treatment. Qual Saf Health Care 2005; 14:371-7.

15. Casaletto JA, Gatt R. Post-operative mortality related to waiting time for hip fracture surgery. Injury 2004;35:114 20.

16. Novack V, Jotkowitz A, Etzion O, Porath A. Does delay in surgery after hip fracture lead to worse outcomes? A multicenter survey. Int J Qual Health Care 2007;19:170-6.

17. Zuckerman JD. Hip fracture. N Engl J Med 1996;334:1519 25.

18. Lau PY. To improve the quality of life in elderly people with fragility fractures. Hong Kong Med J 2016;22:4-5

19. Simunovic N, Devereaux PJ, Sprague S, et al. Effect of early surgery after hip fracture on mortality and complications: systematic review and meta-analysis. CMAJ 2010;182:160916.

20. Chief Executive's Progress Report on Key Performance Indicators (KPI Report No. 29, December 2015). Available from: https://www.ha.org.hk/haho/ho/cad_bnc/AOMP1169.pdf. Accessed Sep 2016.

21. Lau TW, Fang C, Leung F. The effectiveness of a geriatric hip fracture clinical pathway in reducing hospital and rehabilitation length of stay and improving short-term mortality rates. Geriatr Orthop Surg Rehabil 2013;4:3-9.

22. Nyholm AM, Gromov K, Palm H, et al. Time to surgery is associated with thirty-day and ninety-day mortality after proximal femoral fracture: a retrospective observational study on prospectively collected data from the Danish fracture database collaborators. J Bone Joint Surg Am 2015;97:1333-9.

23. Royal College of Physicians. National Hip Fracture Database annual report 2015. Available from: http://www. nhfd.co.uk/nhfd/nhfd2015reportPR1.pdf. Accessed Jun 2016.

24. Leung AH, Lam TP, Cheung WH, et al. An orthogeriatric collaborative intervention program for fragility fractures: a retrospective cohort study. J Trauma 2011;71:1390-4.

25. Vidán M, Serra JA, Moreno C, Riquelme G, Ortiz J. Efficacy of a comprehensive geriatric intervention in older patients hospitalized for hip fracture: a randomized, controlled trial. J Am Geriatr Soc 2005;53:1476-82.

26. Friedman SM, Mendelson DA, Kates SL, McCann RM. Geriatric co-management of proximal femur fractures: total quality management and protocol-driven care result in better outcomes for a frail patient population. J Am Geriatr Soc 2008;56:1349-56.

27. Thwaites JH, Mann F, Gilchrist N, Frampton C, Rothwell A, Sainsbury R. Shared care between geriatricians and orthopaedic surgeons as a model of care for older patients with hip fractures. N Z Med J 2005;118:U1438.

28. Ho AW, Wong SH. Orthogeriatric collaborative intervention program for hip fracture surgery: A review on southern Chinese population. Osteoporos Int 2016;27(Supp 1):P400.

29. Orosz GM, Hannan EL, Magaziner J, et al. Hip fracture in the older patient: reasons for delay in hospitalization and timing of surgical repair. J Am Geriatr Soc 2002;50:133640.

30. Chau PH, Wong M, Lee A, Ling M, Woo J. Trends in hip fracture incidence and mortality in Chinese population from Hong Kong 2001-09. Age Ageing 2013;42:229-33. 